Hansen, C., M. L. Kaplan, S. A. Mensing, S. J. Underwood, J. M. Lewis, K. C. King, and J. E. Haugland, 2013: They just don't make storms like this one anymore: Analyzing the anomalous record snowfall event of 1959. J. Operational Meteor., 1 (5), 52-65, doi: http://dx.doi.org/10.15191/nwajom.2013.0105.

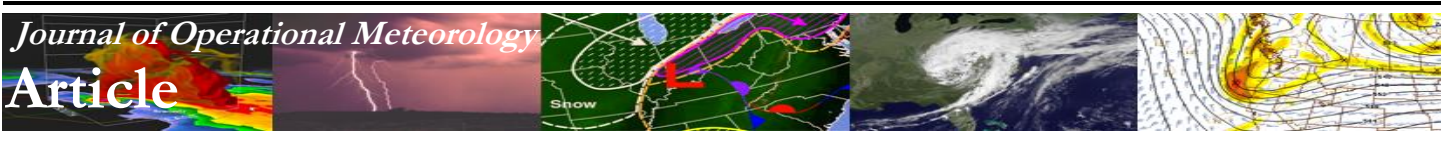

\title{
They Just Don't Make Storms Like This One Anymore: Analyzing the Anomalous Record Snowfall Event of 1959
}

\author{
CASSANDRA HANSEN \\ Department of Geography, University of Nevada, Reno, Nevada \\ MICHAEL L. KAPLAN \\ Division of Atmospheric Sciences, Desert Research Institute, Reno, Nevada \\ SCOTT A. MENSING \\ Department of Geography, University of Nevada, Reno, Nevada \\ S. JEFFREY UNDERWOOD \\ Department of Geology and Geography, Georgia Southern University, Statesboro, Georgia \\ JOHN M. LEWIS \\ Division of Atmospheric Sciences, Desert Research Institute, Reno, Nevada \\ NOAA/National Severe Storms Laboratory, Norman, Oklahoma \\ K. C. KING \\ Division of Atmospheric Sciences, Desert Research Institute, Reno, Nevada \\ JAKE E. HAUGLAND \\ Department of Geography, University of Nevada, Reno, Nevada
}

(Manuscript received 19 November 2012; in final form 8 February 2013)

\begin{abstract}
Extreme weather events are rare but significantly impact society making their study of the utmost importance. We have examined the synoptic features associated with a historic snowfall during February 1959 on Mt. Shasta in northern California. Between 13-19 February, Mt. Shasta received $480 \mathrm{~cm}$ of snow and set a single snow-event record for the mountain. The analysis of this event is challenging because of sparse and coarse-resolution atmospheric observations and the absence of satellite imagery; nonetheless, the analysis has contributed to our understanding of synoptic and mesoscale dynamics associated with extreme snowstorm events. We have used an array of methods ranging from the National Centers for Environmental Prediction/National Center for Atmospheric Research reanalysis datasets, analysis of regional sounding and precipitation data, archived newspaper articles, and reminiscences from long-term residents of the area. Results indicate that a single mechanism is unable to produce a snowstorm of this magnitude. Synoptic components that phased several days prior to this event were the following: 1) amplification and breaking of Rossby waves, 2) availability of extratropical moisture that included enhanced midlevel moisture in the 850600-hPa layer, 3) the transition from a meridional to zonal polar jet, and 4) an active subtropical jet stream. The timing and phasing of the northern and southern branches of the polar jet stream led to an idealized long-term juxtaposition of moisture and cold air. This optimal phasing within the circulation pattern was key to the production of record snowfall on Mt. Shasta.
\end{abstract}

\section{Introduction}

Snowfall on Mt. Shasta $\left(41^{\circ} \mathrm{N}, 122^{\circ} \mathrm{W}\right)$, and its melt, is a critically important source of water for the entire state of California. This mountain is the penultimate peak in the southern end of the Cascade Range volcanic chain (Fig. 1a).

Corresponding author address: Cassandra Hansen, Department of Geography, University of Nevada, Mailstop 0145, Reno, NV 89557

E-mail: cassie.hansen@gmail.com 


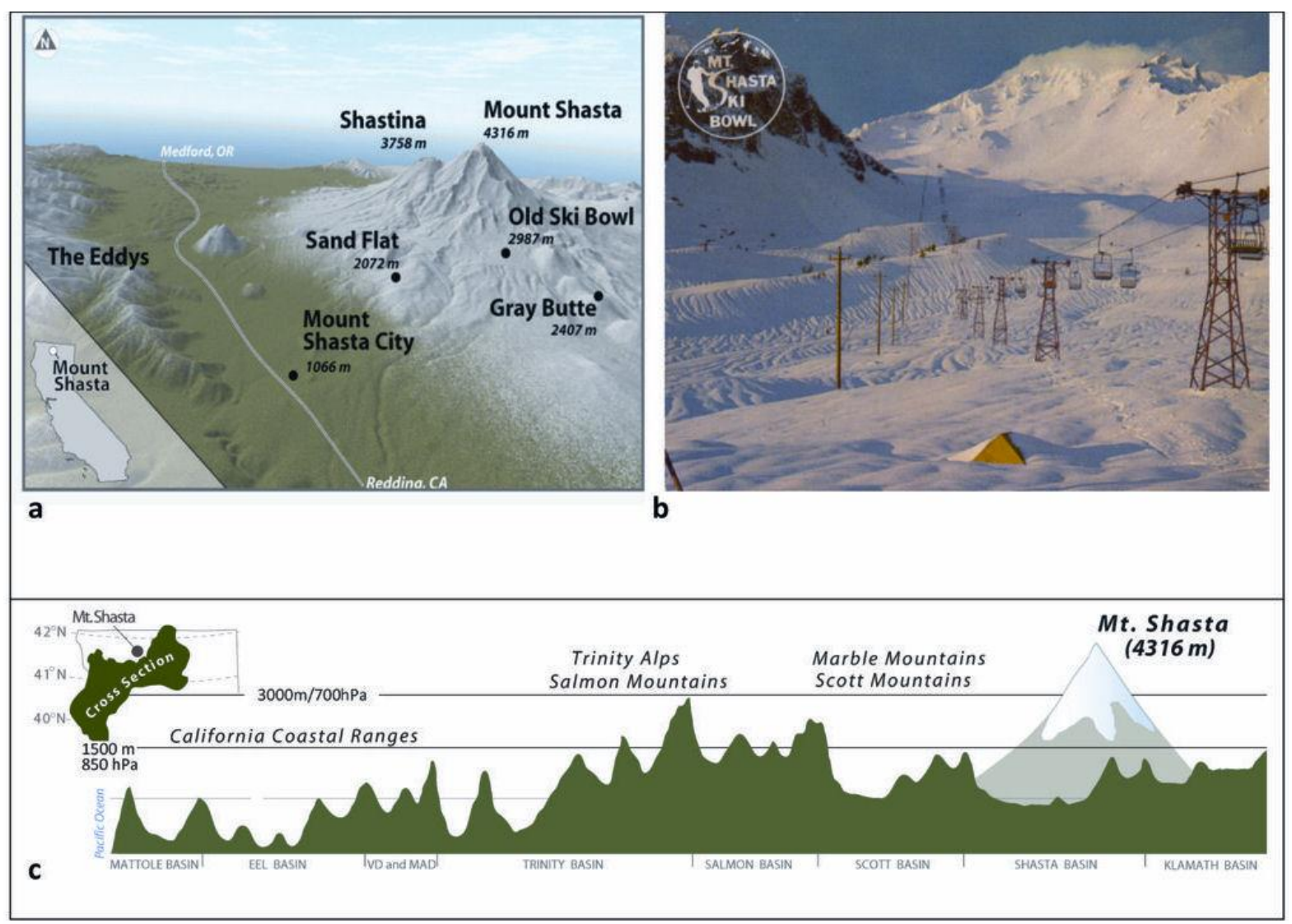

Figure 1. a) Location map of the Mount Shasta region. Black dots are weather stations referenced in Hansen and Underwood (2012). b) The Mt. Shasta Old Ski Bowl chair lift after the 1959 snowstorm where record snowfall was measured (postcard courtesy of College of the Siskiyous' Mt. Shasta Special Collection). c) Elevation profile starting at the eastern edge of the Pacific Ocean, from King Range eastward to Winter Range. Note the complex terrain inland from the Pacific Ocean to Mt. Shasta, and the height of Mt. Shasta overall. Midlevel pressure levels and corresponding heights are identified from 850-700 $\mathrm{hPa}$. VD refers to Van Dozer and MAD refers to the Mad River basin. Image courtesy of Kelso Cartography (portfolio.kelsocartography.com/index.php?album=hsu-6rivers). Click image for an external version; this applies to all figures hereafter.

Eastward progressing storms must pass over three mountain ranges in order to reach Mt. Shasta (Fig. 1c). These orographic barriers require the duration and intensity of one single storm to be more anomalous for an abundance of precipitation to reach Mt. Shasta. The volcanic cone of Shasta rises $3048 \mathrm{~m}$ above mean sea level and forms the apex for three adjoining watersheds: the Klamath Watershed (north), Upper Sacramento (south), and McCloud Watershed (east). The Sacramento River is the longest river entirely within the state of California $(719 \mathrm{~km}$ or $447 \mathrm{mi}$ ) and it is the major fluvial source of water flow between the northern and central sections of the state (Fig. 1c).

Mt. Shasta has a long record of extreme snowstorms. One of the most famous occurred in April 1875, stranding John Muir and his guide for a night (Muir 1877). In January 1890 one storm accumulated $3.6 \mathrm{~m}$ of snow, halting railroad transportation and trapping 116 passengers for over sixty hours (Southern
1932). Local newspapers described this storm as "...the fiercest storm that ever roared down the Sacramento Canyon" (Asbell 1959b). Both of these storms have been eclipsed by the record-breaking snowstorm of 1959.

Between 13-19 February 1959, approximately 4.8 $\mathrm{m}$ of snow fell on Mt. Shasta - the greatest amount in a single continuous snowstorm recorded in North America to that date. This record went unmatched and unbroken until the early 1990s (Freeman 2011). The snowfall in this extreme event is a sizable fraction of the average yearly snowfall on Mt. Shasta. Extreme (high impact) weather events such as the 1959 storm provide researchers with a unique opportunity to explore the dynamics of weather phenomena - at times an exceptional display of the fusion among many different dynamical processes. While it is important to investigate these extreme events, reliable observations are missing because the events occurred before this 
new age of technologically advanced instruments (O'Hara et al. 2009; Dettinger 2011). Even in the presence of detailed journals, such as those available from members of the Donner Party, reconstruction of weather events has proved problematic (Stewart 1936; DeVoto 1943). In this regard, we are indeed fortunate in our study of the 1959 Mt. Shasta snowstorm; not only have we had access to reminiscences of the 1959 storm from long-term residents of the Mt. Shasta region, we also have been able to access routine upperair observations that commenced a decade earlier. These upper-air data serve as valued input to the reanalysis datasets that blend observations with retrospective dynamical forecasts. We use these datasets to analyze key synoptic and mesoscale atmospheric processes germane to the $1959 \mathrm{Mt}$. Shasta snowstorm.

\section{a. Summary of the 1959 storm event}

The Mt. Shasta Old Ski Bowl resort opened the 1958-59 ski season with the first snowfall in January, an unusually late start to the season. The resort is situated above the tree line (elevation $\sim 2987 \mathrm{~m}$ ) in an area routinely inundated by whiteouts, avalanches, and road closures. The lack of snowpack in 1959 was of sufficient concern that a local Klamath Native American by the name of Ty-You-Na-Sch was persuaded to perform the tribes' ancient rock ceremony to bring snow to the Mt. Shasta region (Freeman 2011). The five-day storm began on Friday, 13 February, and the first two days of the storm brought $83 \mathrm{~cm}$ of dry snow to Mt. Shasta City. During the following three days the temperatures and the water content in the snow increased, causing "leadheavy snow and slush" (Asbell 1959b). The month of February recorded the greatest snowfall for that month in twenty years and the third greatest since records began in 1888 (Asbell 1960).

A "snowstorm event" is defined by Changnon (2006) as having $15.2 \mathrm{~cm}$ or more of snow that falls over a one-to-two-day period. In California, extreme precipitation events usually occur over a three-day period (Dettinger 2011). The 1959 storm had continuous snowfall for six days, averaging $80 \mathrm{~cm} \mathrm{dy}^{-1}$ $\left(\sim 3 \mathrm{~cm} \mathrm{hr}^{-1}\right)$, as measured at the Old Ski Bowl. Snowfall produced 24-ft drifts-closing mountain roads and stranding ski park employees at the lodge (Asbell 1960). Substantial snowfall accumulation also was recorded in the city of Mount Shasta (approximately $1921 \mathrm{~m}$ lower than the Old Ski Bowl).
Snowfall accumulation in the town of Mt. Shasta for the month of February averages $185 \mathrm{~cm}$, placing the February 1959 period within the top $6 \%$ of its annual snowfall (WRCC 2011). As a result of the heavy snowfall in town $(125 \mathrm{~cm})$, structural damage was reported at local businesses in Mt. Shasta and local transportation was paralyzed (Asbell 1959a). Clearly, the snowfall accumulation recorded during the February 1959 storm period represented an extreme snowfall event for both Mount Shasta City and the Old Ski Bowl (Fig.1b).

\section{b. West Coast winter storm patterns}

The dominant synoptic circulation patterns associated with West Coast winter storms are identified by: 1) Rossby wave orientation and breaking, 2) existence and location of atmospheric rivers, 3) position of the southern/subtropical jet stream/jet streak, and 4) location of the northern/polar jet stream/jet streak.

Planetary circulation patterns generally include a series of mid-latitude waves that circle both hemispheres-known as Rossby waves (RW), following their discovery in the late-1930s by $\mathrm{C}$. Rossby and associates (Rossby et al. 1939; historically reviewed by Platzman 1968). The reader is referred to Holton (1983) for a thorough discussion of the RW in the context of absolute and potential vorticity conservation. The orientation of a RW can enhance or block the progression of mid-latitude storms; in particular, it can enhance or impair moisture transport from lower latitudes and advection of cooler air from Arctic regions as it controls atmospheric steering patterns. The intensification of a cyclone is associated with the vertical coupling of upper- and lower-level potential vorticity (PV) maxima (Bosart and Lackmann 1995) accompanying transient RW propagation.

The RW trough axes can be oriented positively (northeast-southwest), neutral (north-south), or negatively (northwest-southeast), which affects the distribution of PV. RW breaking results in the shift of the RW axis to a positive tilt causing the overturning of meridional PV, which occurs rapidly and is an irreversible process (McIntyre and Palmer 1983; Abatzoglou and Magnusdottir 2006; Rivière and Orlanski 2007; Strong and Magnusdottir 2008). RW breaking can significantly impact the large-scale latitudinal circulation from the extratropics to the tropics (Abatzoglou and Magnusdottir 2006). RW 
breaking, cyclone development, and differential meridional transport of heat, moisture, and momentum are all strongly coupled phenomena. Weaver (1962) analyzed a 1955 flood event that affected Californiafocusing on low-latitude storm types. In this analysis, Weaver discussed the importance of a RW blocking pattern associated with moisture waves along with the rarity of having a storm centered over the northern two-thirds of California, a phenomenon similar to the 1959 storm. Records of heavy precipitation events were categorized by Weaver (1962), but our understanding of these moisture-laden mid-latitude cyclones continues to expand with the advancements of technology (Dettinger 2011).

Some of the first northwestern United States synoptic winter-storm classification was performed by Krick and Flemming (1954) and Weaver (1962), identifying critical hydrologic storm patterns for California. Krick and Flemming (1954) described and classified six common storm sequences over the eastern Pacific from 40 years of storm pattern information encompassing 1899-1939. Weaver (1962) analyzed a 1955 flood event that affected California focusing on the low-latitude storm types using back trajectories. Continued discussion about this particular storm by Weaver involved examples of the strong transport of moist air from lower latitudes with a storm pattern reflecting what is colloquially known as the pineapple-express pattern.

Synoptic-scale circulation patterns associated with heavy winter season precipitation in California are commonly called the "pineapple-express" or "mangoexpress," referring to the geographic origination of moisture plumes that arrive from the tropics and/or subtropics (Higgins et al. 2002; Dettinger et al. 2004, 2012; Dettinger 2011). The "pineapple-express" pattern was first identified in 1959 and was described in a National Weather Service (NWS) forecast prior to the Mt. Shasta storm. Forecaster W. J. Denney from the San Francisco NWS office predicted that the scale of the 1959 "Valentine's Day" storm had the potential to affect regions of California, Nevada, and Idaho with heavy precipitation, flooding of lower regions, and hurricane strength winds (McLaughlin 2011). The journal Monthly Weather Review discussed the days leading up to this record snowfall with cutoff lows and high-over-low blocking events (i.e., Rex blocks) contributing to the duration and magnitude of this storm event (O'Connor 1959). Moisture transport within the mid-latitudes is sometimes described as a "warm conveyor belt" (Browning 1986) or as a narrow, tropical low-level moisture plume, at approximately $1-2.5 \mathrm{~km}$ altitude in the troposphere (Ralph et al. 2004). These mid-latitude moisture flows, referred to as "atmospheric rivers" (ARs), are associated with heavy West Coast precipitation (Zhu and Newell 1998; Dettinger et al. 2004; Ralph et al. 2004; Neiman et al. 2008; Kaplan et al. 2009; Underwood et al. 2009). Globally, ARs transport approximately $90 \%$ of water vapor from low latitudes to higher latitudes (Ralph et al. 2004). At any given time, multiple rivers extending for $1000 \mathrm{~s}$ of $\mathrm{km}$ may be present in the northern hemisphere (Zhu and Newell 1998; Neiman et al. 2008; Dettinger 2011; Dettinger et al. 2012). These ARs and their subsequent precipitation contribute to seasonal snowpack and can lead to high snow-water equivalent in the Sierra Nevada (Guan et al. 2010). Present day AR signals are identified with satellite imagery based on the thickness of the moisture plume, amount of water vapor, and the length of connectivity. The identification of historical ARs requires the use of regional soundings to identify moisture-rich surges (precipitable water $>2 \mathrm{~cm}$ ). The $\mathrm{AR}$, or group of ARs for this case study, is/are identifiable from 14-16 February 1959 between latitudes $30^{\circ} \mathrm{N}-42^{\circ} \mathrm{N}$ (Dettinger 2011) and directly west of Mt. Shasta $\left(41^{\circ} \mathrm{N}\right)$ off the California and Oregon coasts.

The combination of ARs paired with 1) an active polar cold pool/jet stream dropping southeastwards from the Gulf of Alaska (PJ) and 2) an active southern jet stream/subtropical jet (STJ) extending westsouthwestward from Hawaii can enhance parcel accelerations, the vertical flux of water vapor, and precipitation rates with substantial release of latent heat (Uccellini et al. 1987). Transverse circulations adjacent to elongated PJs and STJs have been associated with upper- and low-level ageostrophic flow (Bjerknes 1951; Keyser and Shapiro 1986). Vertical lifting required for elevated moisture transport of the AR across complex topography (Fig. 1c) is associated with jet-stream orientation, jet-streak quadrant location (right entrance or left exit), and convective outflows and/or jetlet dynamics. Favorable conditions for strong jet-stream formation are commonly found between regions of contrasting temperature (i.e., boundaries of very cold, dry Arctic air and much warmer, moist air from subtropical regions). Jet streaks, or jetlets, are those segments within the jet stream where winds attain their highest speeds. A jetlet is a mesoscale wind feature that is formed by convection associated with the jet stream 
that triggers a midlevel jet streak (Hamilton et al. 1998). A jetlet is formed by the release of latent heat and the resultant geostrophic adjustment in reaction to heating and pressure perturbations. Latent heat release often occurs in the poleward/left-exit region of the jet streak, along with positive vorticity advection and subsequent lifting. This convective outflow in the leftexit region of a large jet streak can be advected by leftward-directed finescale wind maxima in the midto-upper troposphere (Kaplan et al. 1998). It is here that copious moisture can be elevated and transported above the coastal ranges towards Mt. Shasta.

For ARs to reach the west coast of California and inland to Mt. Shasta, there needs to be additional lifting of ARs to midlevels (850-600 hPa or 1.5-4.5 $\mathrm{km})$ by accompanying jet streaks and jetlets. To maintain the magnitude and duration of the 1959 snowfall event there likely was phasing of the streams, (i.e., PJ and STJ). Furthermore, mesoscale convective systems providing additional lift must have formed days prior to the snowfall event allowing for the progression of AR moisture downstream and convective lifting of moisture high enough (850-600 $\mathrm{hPa}$ or $1.5-4.5 \mathrm{~km})$ to be transported across the complex terrains of the Coastal Range, Trinity Alps, and Marble Mountains to Mt. Shasta.

The coarse resolution of datasets and infrequent data availability create challenging conditions for analysis of historic weather events. The use of regional and local meteorological data, combined with personal accounts and archived news articles, help to recreate the historical weather events. Moreover, the modern analytical techniques allowed insight into the complexity of this historical event. This analysis is the first of a series of storms that will help forecasters identify the specific atmospheric dynamics associated with these extreme snowfall events on Mt. Shasta, California.

\section{Atmospheric datasets/methodology}

\section{a. Synoptic-scale observational reanalysis data}

The historic analysis of the 1959 snowstorm is limited to time-relative daily charts from the National Oceanic and Atmospheric Administration (NOAA) National Centers for Environmental Prediction/ National Center for Atmospheric Research (NCEP/NCAR) reanalysis database (grid of $2.5^{\circ}$ latitude $\times 2.5^{\circ}$ longitude) that were created at 24-h intervals (represented as T-72, T-48, T-24 and T-00 h prior to the first snowfall) (Kalnay et al. 1996). The reanalysis plots used in the analysis start at T-192, eight days prior to the storm.

\section{b. Regional (meso- $\alpha$ scale) observational data}

Long-term surface data were used to identify periods of rain and snowfall at Los Angeles (LAX), Salinas (SAL), Sacramento (SAC), Santa Rosa (SROSA), Redding (RED), and Arcata (HUM), California. Monthly regional precipitation (rain and snowfall) data from the Western Regional Climate Center (WRCC 2011) provided a regional spatial distribution of precipitation. Atmospheric radiosonde datasets archived from Plymouth State Weather Center (vortex.plymouth.edu) were used to recreate and validate regional dynamics at 0000 UTC and 1200 UTC for Oakland, California (OAK station number 72493), Medford, Oregon (MFR station number 72597), Reno, Nevada (REV station number 72489), San Diego, California (NKX station number 72293), and Vandenberg, California (VBG Air Force Base station number 72393). These data were used to obtain a regional perspective on the vertical moist thermodynamic structure of the atmosphere for integrated precipitable water, convective available potential energy (CAPE), and the vertical temperature profile.

\section{c. Historical archives and local interviews}

Historic surface data along with archived newspaper articles from Northern California libraries were used to obtain a substantial record of the 1959 snowfall. Archival documents were collected at the College of the Siskiyous' Mount Shasta Special Collection Library in Weed, California. Regional searches were conducted to contact people living in or near Mt. Shasta at the time of the storm. Long-term residents with local knowledge were surveyed. Thirty surveys were sent out in the first stage of the questionnaire using a snowball surveying techniquea non-probability method used with populations that are inaccessible (StatSoft 2010). This method relies on referrals from initial subjects to determine additional interviewees. In this case, the initial referrals suggested ten more possible subjects for the questionnaire expanding the results to 34 questionnaires (Hansen and Underwood 2012). 


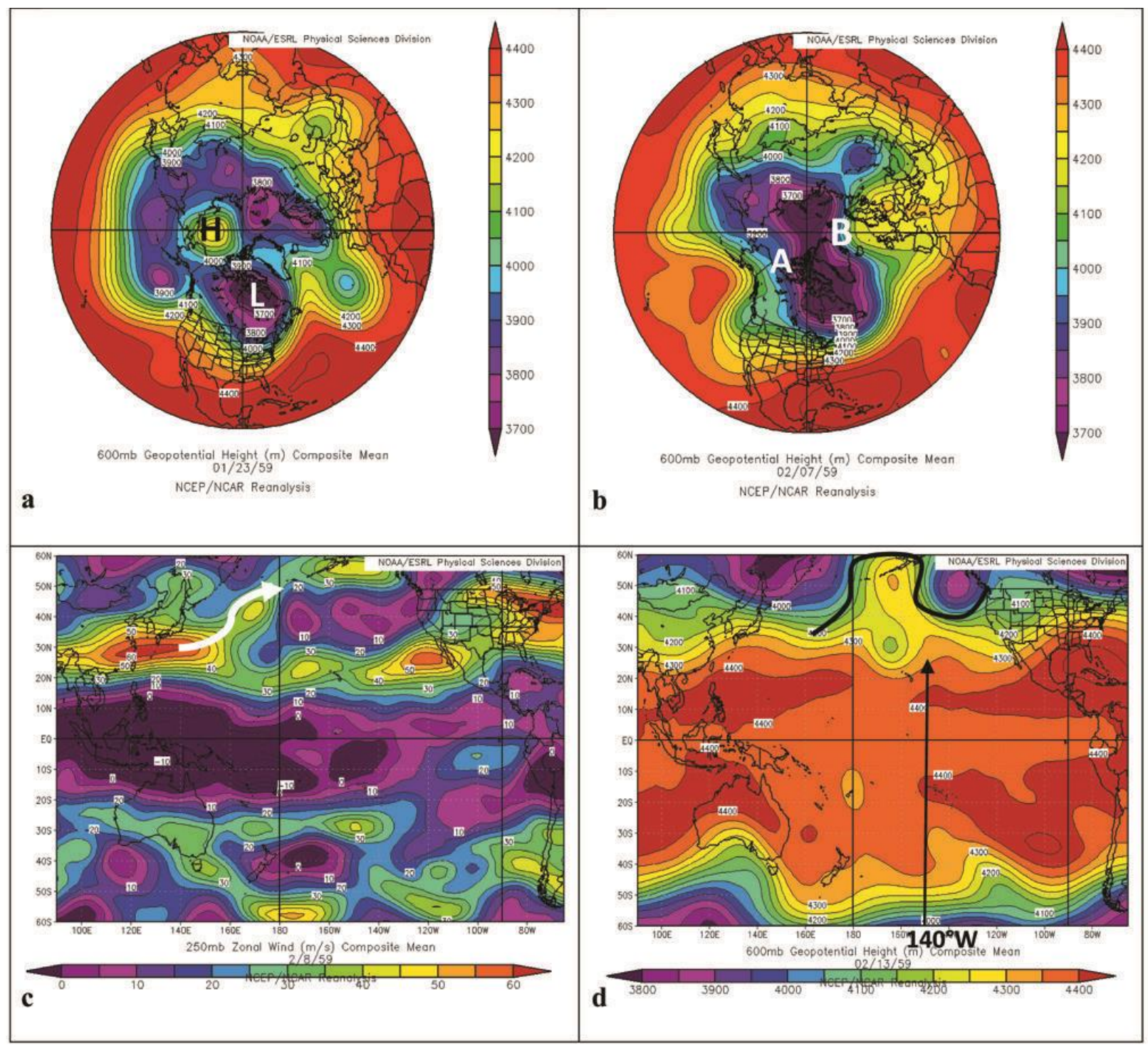

Figure 2. Northern branch composite anomaly (computed using 1981-2010 baseline) and mean plots for: a) 23 January 1959, mean 600$\mathrm{hPa}$ geopotential height (gpm); the letters $\mathrm{H}$ and $\mathrm{L}$ represent high and low pressure; b) February 1959 composite mean Northern Hemisphere 600-hPa geopotential height; letter A represents the eastern Pacific Ridge and letter B the ridge over Atlantic/Europe; c) 8 February 1959 composite mean 250-hPa zonal wind $\left(\mathrm{m} \mathrm{s}^{-1}\right)$; arrows represents the meridional movement of air northward and southward in response to the blocking ridge; and d) 13 February 1959 composite mean of 600-hPa geopotential height (gpm), where the black line represents the dominant ridge. Images courtesy Earth System Research Laboratory interactive plotting and analysis webpage.

\section{d. NCEP/NCAR reanalysis}

Time-relative analyses from the NOAA NCEP/NCAR reanalysis database were created at 24-h intervals (represented as T-192 to T-00 h prior to the 1959 snowstorm event) (Kalnay et al. 1996). Pacific Basin plots allow synoptic signals to be identified using 17 pressure levels and 28 sigma (terrainfollowing) levels. This analysis method is similar to the synoptic-scale compositing procedures used to identify spill-over floods (Underwood et al. 2009) and synoptic avalanche conditions (Hansen and
Underwood 2012). The specific charts are: $250-\mathrm{hPa}$ geopotential heights and winds, 600-hPa geopotential heights, 500-hPa geopotential heights and winds, 700$\mathrm{hPa}$ geopotential heights and winds, $1000-500-\mathrm{hPa}$ column thicknesses, and precipitation rates $\left(\mathrm{mm} \mathrm{dy}^{-1}\right)$. Charts were created eight days prior to the first period of snowfall observed at the Old Ski Bowl.

\section{Results and discussion}

The 1959 analysis will identify synoptic dynamic/thermodynamic features and patterns from a 
relatively low-to-high frequency perspective starting with: a) analysis of the northern stream synoptic dynamics eight days (T-192 h) prior to the snow event, b) analysis of the southern stream synoptic dynamics eight days (T-192 h) prior to the snow event, c) phasing of the two streams (northern and southern) to explain the dynamic forcing prior to and during the 13-18 February snowfall event, and d) identification of the mesoscale forcing component of the phasing of the two streams three days before and during the event using regional data. Here the term "stream" is defined as a coherent zone of propagating RWs and/or uppertropospheric wind/jet maximum.

\section{a. Observed Pacific synoptic overview focusing on the northern stream 8 days prior to the event $(6$ February-13 February 1959)}

During the first week of February the eastern Pacific RW was in retrogression. The large-scale ridge remained stationary between $160^{\circ} \mathrm{W}$ and $125^{\circ} \mathrm{W}$ for the majority of January into February, blocking and deflecting moisture and momentum poleward and limiting the penetration of cold Arctic air into lower latitudes. This resulted in warmer than normal temperatures on the west coast of the United States as observed in Los Angeles and San Francisco with temperature deviations of $3.2^{\circ} \mathrm{C}$ and $2.4^{\circ} \mathrm{C}$, respectively (O'Connor 1959). A deeper than normal polar vortex center (L), roughly 15 dam below normal, developed and maintained its position over the Baffin Islands in northeastern Canada, blocking the downstream flow approaching the north Atlantic (Fig. 2a).

For most of January and into the second week of February, low pressure over northeastern North America continued to be blocked by a strong ridge over the Pacific and a second ridge over the Atlantic, hindering any Arctic air from propagating to lower latitudes (Fig. 2b, Letter A). By early February, however, a companion polar vortex amplified over northeastern Siberia and the Bering Sea creating a balanced, high-latitude Northern Hemispheric circulation with two very long waves in quasiequilibrium (i.e., a trough/ridge system) over eastern North America and the western Atlantic, and over eastern Asia and the western Pacific (Fig. 2b, Letter B). During January 1959 the Arctic Oscillation (AO) index shifted from a negative monthly AO index $(-2.013)$ to a positive index (2.544) (NOAA 2012), indicating a shift from high to low pressure over the
Arctic region (Fig. 2a, Letter $\mathrm{H}$ ), and leading to displacement of Arctic air to lower latitudes (Fig. 2b) during the month of February. A positive AO allows for the northward progression of storms bringing wetter conditions to higher latitudes such as Alaska and Northern Europe. Areas located at mid-latitudes $\left(45^{\circ} \mathrm{N}\right)$ such as California, Spain, and the Middle East experience drier conditions (NOAA 2012). Although the first week in February reflected these drier than normal conditions, a shift in the AO index between week 1 and week 2 occurred to provide and transport moisture from the tropics to mid-latitudes.

The long-wave features enhanced the eastern Pacific jet stream by 8 February (Fig. 2c; T-168), strengthening the preexisting steep meridional geopotential height gradient over the central and eastern Pacific between the deepening polar vortex over northern Siberia and high geopotential heights over Oceania and southeastern Asia. The large polar vortex remained over the region because of blocking downstream. The intensification of this vortex contributed to the combination of Arctic air (over Siberia) that spilled over warmer water (Pacific Ocean) creating a strong moisture flux (Businger and Reed 1989). Over the western Pacific, the jet at 250$\mathrm{hPa}$ reached an extreme magnitude on 8 February 1959 (T-144) with maximum zonal winds of $60 \mathrm{~m} \mathrm{~s}^{-1}$ over southern Japan. The core of the jet remained centered off the southeastern coast of Japan between $120^{\circ} \mathrm{E}$ and $140^{\circ} \mathrm{E}$ for five days in response to the stationary ridge downstream (Fig. 2c).

On 9, 10, and 11 February, at 700-hPa, maximum zonal winds ranged from $25-30 \mathrm{~m} \mathrm{~s}^{-1}$ and the lowlevel jet below 700-hPa actively transported moisture to higher latitudes $\left(40^{\circ} \mathrm{N}-60^{\circ} \mathrm{N}\right)$ due to the meridional deflecting effect of the stationary ridge downstream as well as the transverse circulation in the new mid-toupper tropospheric jet streak. On 12 February (T-48) the ridge amplified poleward of $60^{\circ} \mathrm{N}$ and tilted from a negative/neutral to a positive (northeast-southwest) orientation, resulting in a RW break on 13 February and baroclinic amplification of the trough downstream/east of the wave break over the northeastern Pacific at approximately $140^{\circ} \mathrm{W}$ (Fig. 2d). This positive tilt reflects the rapid overturning of meridional PV previously identified by McIntyre and Palmer (1983), Abatzoglou and Magnusdottir (2006), Rivière and Orlanski (2007), and Strong and Magnusdottir (2008). 


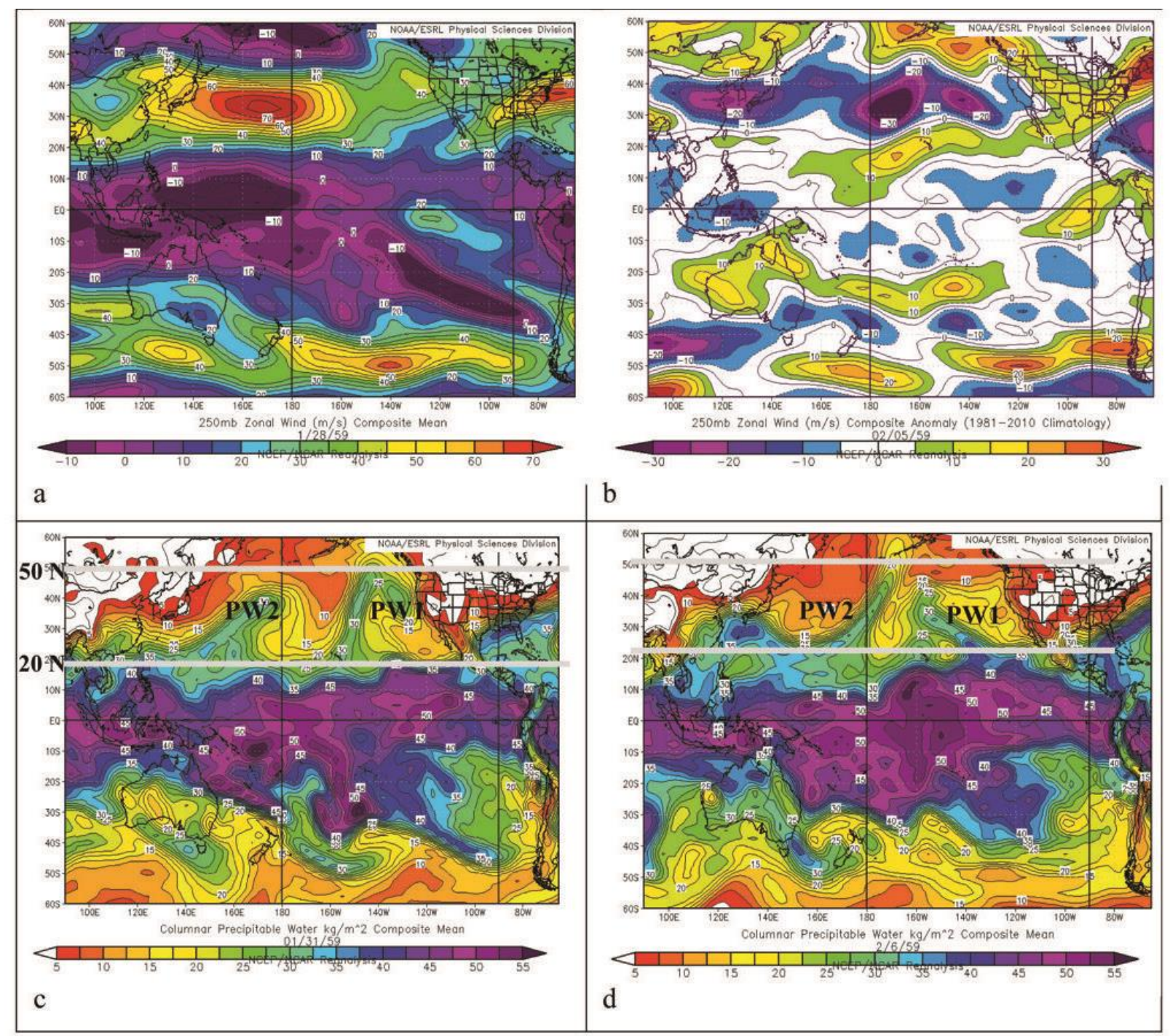

Figure 3. Southern branch composite anomaly (computed using 1981-2010 baseline) and mean plots for: a) 28 January 1959, mean 200$\mathrm{hPa}$ zonal wind $\left(\mathrm{m} \mathrm{s}^{-1}\right)$; b) 5 February 1959 composite 200-hPa zonal wind $\left(\mathrm{m} \mathrm{s}^{-1}\right)$; c) 31 January 1959 columnar precipitable water (kg $\left.\mathrm{m}^{-2}\right)$; and d) 6 February 1959 columnar precipitable water $\left(\mathrm{kg} \mathrm{m}^{-2}\right)$. Images courtesy Earth System Research Laboratory interactive plotting and analysis web page.

b. Synoptic overview focusing on the southern stream 8 days prior to the event (6 February-13 February 1959)

The dominant synoptic feature of the southern jet stream/STJ is the longevity of the stream coupled with the transport of copious moisture to northern latitudes. The southern stream is an important component in this storm's formation because it is associated with sporadic periods of strong convection typically followed by heavy precipitation. The activity in this southern stream was apparent as early as the last week in January. The arrival of the first plume of moisture (PW1) coincident with jet strengthening began 28
January. The unbalanced flow of the jet was consistent with the acceleration of air parcels within the exit region. During this period, a strong zonal jet (maximum core velocity of $70 \mathrm{~m} \mathrm{~s}^{-1}$ ) elongated off the east coast of Japan and propagated over the Pacific south of $35^{\circ} \mathrm{N}$ latitude (Fig. 3a).

The presence of this jet 19 days prior to the first snowfall was important to the longer period orientation and availability of the moisture for the Mt. Shasta event. The southern jet stream was considerably active eight days prior to and during the snowfall event as illustrated by anomalies in $200-\mathrm{hPa}$ wind velocities (compared to the 40-year climatology; Fig. 3b). A moist tongue or river (PW1) was already established in 
mid-latitudes over the Pacific, awaiting subsequent enhancement by future transverse ageostrophic circulations accompanying jet streaks in advance of the Mt. Shasta snowfall event (Figs. 3c-d).

During this period of time, an extensive band of moisture was centered near $20^{\circ} \mathrm{N}$ to $20^{\circ} \mathrm{S}$ and $140^{\circ} \mathrm{E}$ to $80^{\circ} \mathrm{W}$ (Fig. 3c). This plume of warm moist air (PW1) was transported northeastward by the low-level return branch of the polar jet on 28 January 1959 (T-456; Fig. 3a). Interestingly, PW1 never made landfall during this eight-day period but continued to elongate north of the equatorial warm pool of available moisture centered south of the Hawaiian Islands.

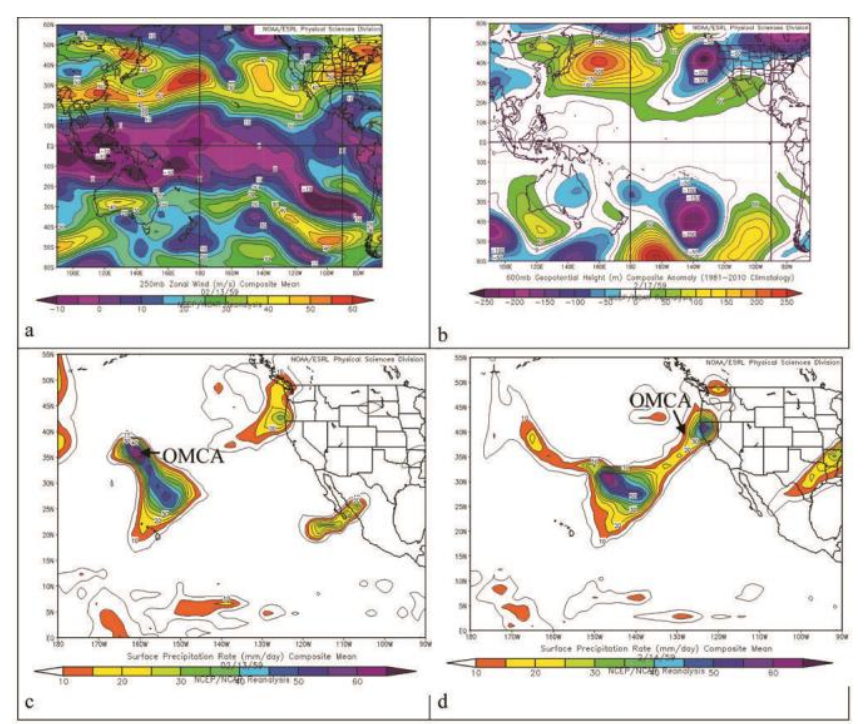

Figure 4. Northern and southern branch composite anomaly (computed using 1981-2010 baseline) and mean plots for: a) 13 February 1959 mean 200-hPa zonal wind $\left(\mathrm{m} \mathrm{s}^{-1}\right)$; b) 12 February 1959 composite anomaly geopotential height (m); c) 13 February 1959 surface precipitation rate $\left(\mathrm{mm} \mathrm{dy}^{-1}\right)$; and d) 14 February 1959 surface precipitation rate $\left(\mathrm{mm} \mathrm{dy}^{-1}\right)$. OMCA refers to oceanic mesoscale convective system. Images courtesy Earth System Research Laboratory interactive plotting and analysis web page.

\section{c. Phasing of the northern and southern stream prior to and during the snowfall event (6 February-13 February 1959)}

Eight days prior to the snowfall event the combination of 1) the northern stream's stationary ridge over the Pacific, 2) the blocked Polar vortex, and 3 ) the southern stream's recirculating tropical moisture and additional embedded convection collectively remained in a blocking pattern. By the second week of 13 February the west coast ridge aloft and the eastern Pacific high retrograded approximately $15^{\circ}$ from their stationary position the previous week to a new longitude of $150^{\circ} \mathrm{W}$ (Fig. 4a).

The shift in position of the ridge and the orientation (shifting positive) of the RW permitted the blocked cyclonic vorticity maxima (Fig. 4b) to plunge southward along the west coast of North America. Once this southward motion occurred, the original moisture plume, PW1, provided a moisture source for transport to the northeast.

As the southern upper-level jet strengthened the low-level jet also increased in intensity, enhancing the east-northeastward moisture transport towards the California coast. The active southern stream enhanced convection along the California coast and contributed to the CAPE observed in regional soundings, (analyzed in the next section) by virtue of Fig. 4c. The breaking (northeastward overturning) of the RW on 13 February (Fig. 4d; T-24) led to baroclinic amplification of the trough that approached the West Coast of the United States, bringing colder air to lower latitudes and the readjustment of the northern jet from zonal to meridional flow (Fig. 4a). This phasing between the decreasing heights strengthened the north-south height gradient west of the Pacific Coast, resulting in an increase in the southern stream's momentum (i.e., jetogenesis; Fig. 4a).

\section{d. Mesoscale forcing before and during the event (11- 16 February 1959)}

The active southern stream trigged the development of a primary oceanic mesoscale convective system area on 11 February south of the Hawaiian Islands $\left(20^{\circ} \mathrm{N}, 150^{\circ} \mathrm{W}\right)$ with an average moist neutral lapse rate of $-6.7^{\circ} \mathrm{C} \mathrm{km}{ }^{-1}$ between 700-400 hPa (Fig. 4c, labeled OMCA). Moist neutral lapse rates also were identified by Ralph et al. (2004) associated with West Coast high precipitation rates and by Kaplan et al. (2009) associated with midlevel moisture and Sierra Nevada lee-side heavy precipitation. The moist neutral lapse rates occurred 24-48 $\mathrm{h}$ prior to the onset of the heavy snowfall at Mt. Shasta. The subsequent downstream mesoscale convective environment was validated additionally by moist neutral lapse rates until 14 February (Fig. 4d), which was consistent with the collective effect of several oceanic mesoscale convective systems' lifting/vertical transport of moisture to midlevels identified in the Oakland, California (OAK), and Medford, Oregon (MFR), soundings (Fig. 5). 


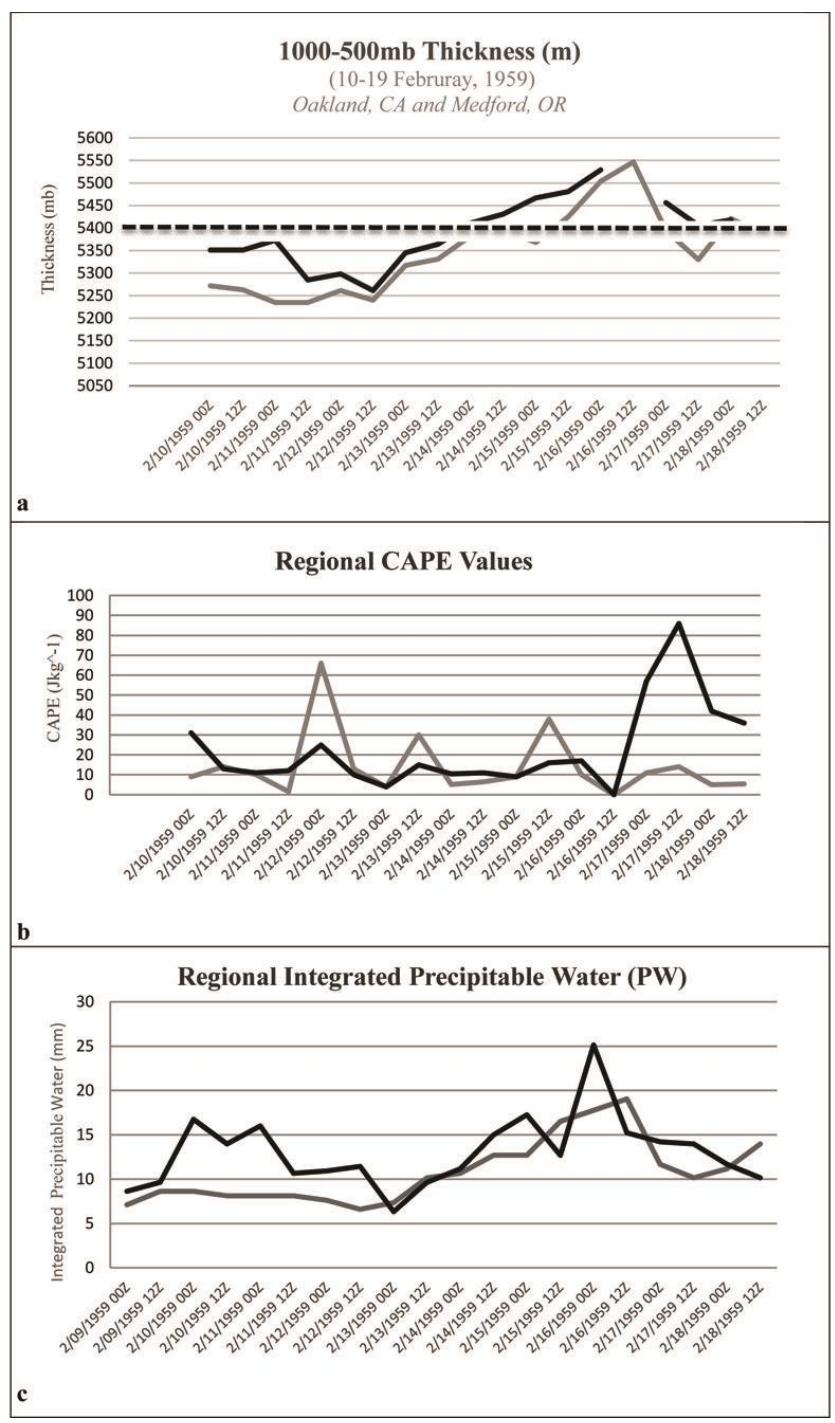

Figure 5. Regional sounding data for 10-19 February 1959 from Oakland, CA (OAK; black line), and Medford, OR (MFR; grey line), showing: a) 1000-500-mb thickness (m) where the black dotted line is the 5400-m thickness value used to detect freezing precipitation; b) Surface based CAPE $\left(\mathrm{J} \mathrm{kg}^{-1}\right)$; and c) integrated precipitable water $(\mathrm{mm})$.

The offshore northern and southern stream configuration began to affect onshore locations identified at OAK and MFR on 0000 UTC 12 February, with distinct changes in the atmospheric thickness (Fig. 5a), CAPE (Fig. 5b), and integrated precipitable water values (Fig. 5c) observed in the vertical columns at OAK and MFR.

The increase of the atmospheric thickness over the sub-synoptic zone-including Mt. Shasta-indicated by the regional soundings on 12 February (Fig. 5a) reflects the change in average temperature and average moisture content between $1000 \mathrm{hPa}$ and $500 \mathrm{hPa}$ and was the result of the weakening of the ridge accompanying the RW and strengthening of the southern stream. The importance of the southern stream's transport on 13 February was identified by warmer air observed at both OAK and MFR, signifying the progression of warmer moist air inland and to higher latitudes. This warm, moist air created an environment favorable for additional convection as inferred from observed regional CAPE values (Fig. $5 b)$. These peak CAPE values correspond to the proximity of the moisture plumes as they made landfall consistent with higher values of integrated water vapor (Fig. 5c).

Three low-level ARs were identified during this February storm by Dettinger (2011) at latitudes appropriate to bring moisture to Mt. Shasta. ARs were classified based on the integrated water vapor greater than $20 \mathrm{~mm}$. The three ARs made coastal landfall on 14 February $\left(40^{\circ} \mathrm{N}\right), 15$ February $\left(42.5^{\circ} \mathrm{N}\right)$, and 16 February $\left(30^{\circ} \mathrm{N}\right)$. The surges of moisture from these low-level ARs are indicated in Fig. 5c with the integrated water vapor at both OAK and MFR, but have precipitable water values less than $20 \mathrm{~mm}$ because of the particular latitude of the ARs and the interior setting of MFR. On 14 and 15 February the moist, unstable air arrived at $0000 \mathrm{UTC}$ at $950 \mathrm{hPa}$ for OAK and $850 \mathrm{hPa}$ for MFR. The vertical wind shear regimes at OAK showed a slight veering pattern (7.5 $\mathrm{m} \mathrm{s}^{-1}$ ) from the surface to $600 \mathrm{hPa}$ and a shift to strong $\left(40 \mathrm{~m} \mathrm{~s}^{-1}\right)$ westerly flow (Figs. 6a,c). The surface winds at MFR were $15 \mathrm{~m} \mathrm{~s}^{-1}$ veering to higher winds of $30 \mathrm{~m} \mathrm{~s}^{-1}$ at the moist level of $850 \mathrm{hPa}$ (Figs. 6a-d). Veering vertical wind shear is consistent with horizontal warm advection.

Perhaps the most interesting feature in Fig. 6 is the warm/moist air layer generally lying at the base of the 650-850-hPa layers indicating an elevated, warm, moist-air plume above the low-level jet. This midlevel warm, moist plume enhanced by the midlevel jet supports the CAPE buildup and moistening of these soundings extending upwards from OAK to MFR in time. This suggests elevated midlevel tropical air extending upstream from Mt. Shasta to north of the Hawaiian Islands where earlier oceanic mesoscale convective system development was observed (Fig. 6). Evidence of this elevated warm air supports findings from Kaplan et al. (2009) that a midlevel river is a key component to transporting moisture inland at higher elevations. The heaviest snowfall periods for this storm took place in temporal proximity to these features at 1800 UTC 15 February (note that data were collected at the same time daily) with $61 \mathrm{~cm}$ recorded 


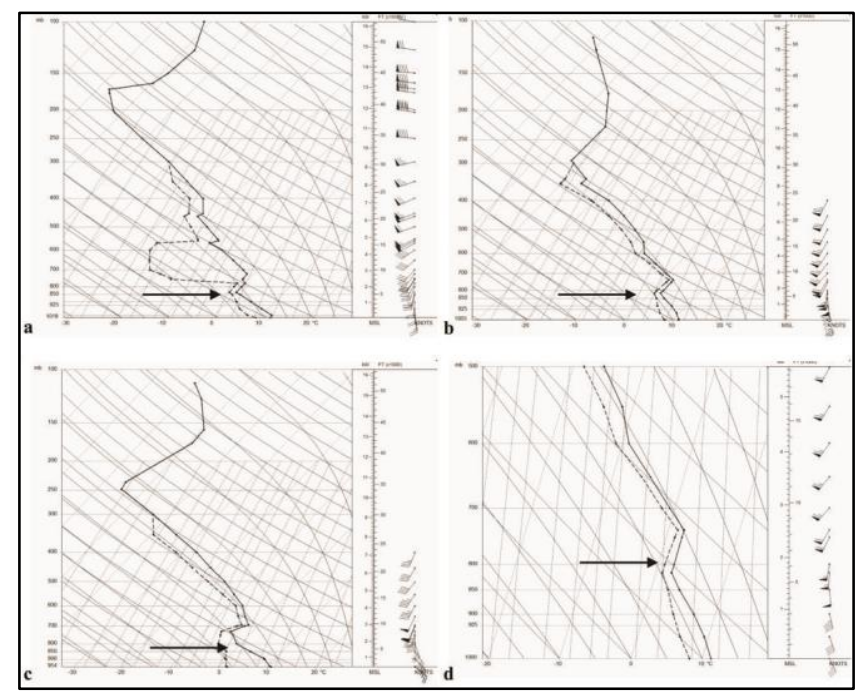

Figure 6. Regional soundings for: a) 0000 UTC 15 February 1959 from Oakland, b) 1200 UTC 15 February 1959 from Medford, c) 0000 UTC 16 February 1959 from Oakland, and d) closer view of 0000 UTC 16 February 1959 from Medford. Arrow indicates moist air between $650-850 \mathrm{hPa}$. Rawinsonde created from NOAA Earth System Research Laboratory (www.esrl.noaa.gov).

at the Old Ski Bowl (Fig. 7a). In the City of Mount Shasta, the heaviest snowfall centered on 1800 UTC 13 February with $68 \mathrm{~cm}$ recorded in town (Fig. 7b).

During this heavy period of precipitation both the MFR and OAK rawinsonde data indicated 1) southerly surface flow of $12.5-15 \mathrm{~m} \mathrm{~s}^{-1}$ with veering southwest winds in the column at speeds of $25 \mathrm{~m} \mathrm{~s}^{-1}$ recorded at $700 \mathrm{hPa}, 2)$ CAPE values at MFR of $38 \mathrm{~J} \mathrm{~kg}^{-1}$ indicating convective potential (Fig. 5b), and 3) veering flow from the surface to midlevels, indicative of a midlevel jetlet accompanying a warm-air plume and horizontal warm advection (Figs. 6a-d).

The midlevel moist air arrived on Mt. Shasta at the Old Ski Bowl on 13 February but the highest 24-h liquid content was observed between 15-16 February with $11.43 \mathrm{~cm}$ (4.5 in) of liquid (Fig. 8) falling and closing Everitt Memorial Highway leading up to the ski resort. The snow survey measurement monitored by the California Department of Water Resources for February 1959 measured $4.6 \mathrm{~m}$ of snow at $2630 \mathrm{~m}$ and $4.1 \mathrm{~m}$ of snow at $2030 \mathrm{~m}$.

The overall snow depth in Mount Shasta City from the February 1959 storm was acknowledged in the personal stories and experiences provided in the surveys. Those who returned the surveys were, on average, about 15 years old in 1959. Multiple stories related the experience of being able to walk out of a second story window onto high snow banks. Another story provided by a store merchant recalled the collapsing of roof tops of local business and residential houses along with the overall closure of the town itself.

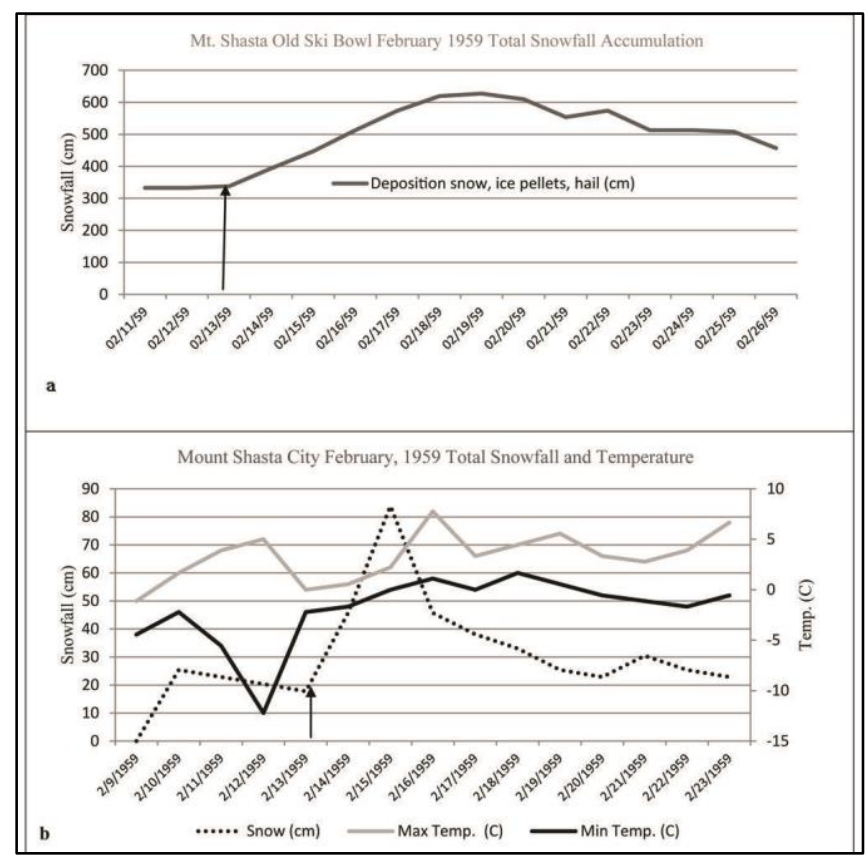

Figure 7. Total snowfall and temperature for a) Old Ski bowl and b) Mount Shasta City. Arrow indicates the time when the snow started to fall and the duration of accumulation associated with this storm.

\section{Summary and conclusion}

The most important findings of this historic storm analysis is the timing and phasing of the northern and southern branches of the jet stream that resulted in such a large volume of snow falling on Mt. Shasta as well as the extraordinarily long precursor period of relatively stationary RW features. The synoptic features, including blocking patterns in the RW weeks prior to the storm, allowed for the accumulation of moisture-laden air from the tropics that eventually reached higher latitudes $\left(\sim 40^{\circ} \mathrm{N}\right)$. The active southern stream-enhanced by the convection from the Hawaiian Islands northeastwards to the region west of the coast of California - contributed to the CAPE observed in regional soundings. This midlevel moisture plume, itself enhanced by the midlevel jet, supports the CAPE buildup and moistening of these soundings from OAK to MFR. This midlevel convective lift is very important because it is necessary to move moisture from low levels (1000$900 \mathrm{hPa}$ ) to midlevels $(850-600 \mathrm{hPa})$, thus making it possible to advect this moisture over the four 


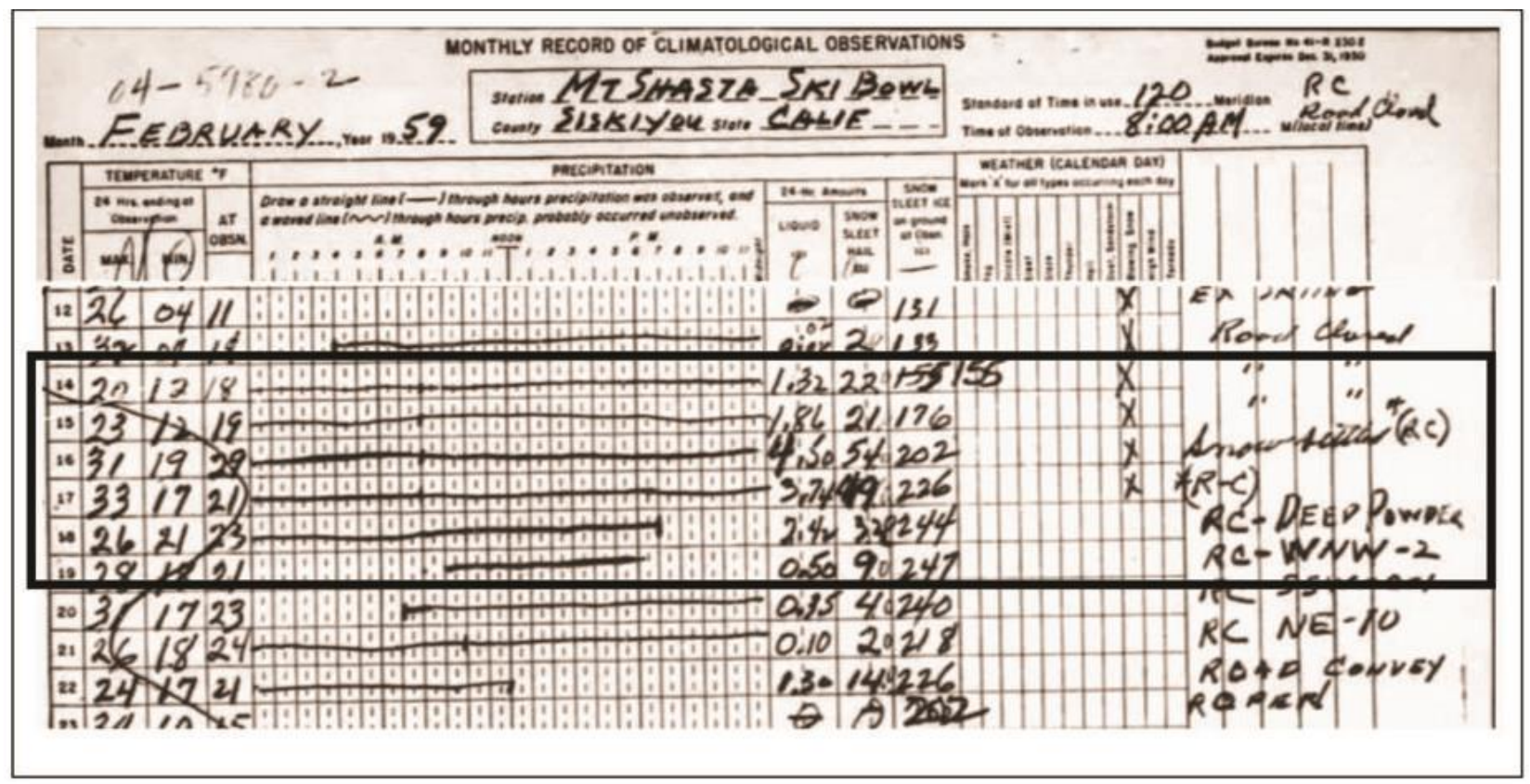

Figure 8. Monthly record of climatological observations at Mt. Shasta Ski Bowl for February, 1959. The observer (RC) notes that the road is closed to the resort. The period of the storm is highlighted in the black box.

mountain ranges (Coastal Range, Trinity Alps, and Marble Mountain) that are located between the coast and Mt. Shasta. The addition of the midlevel moisture ensures that moisture will be available for orographic lifting to the higher levels of Mt. Shasta (that rises abruptly and stands approximately $3000 \mathrm{~m}$ above the surrounding terrain) and not be depleted at lower levels over the upstream mountains.

The retrospective analysis of the large-scale circulation patterns associated with the extreme Mt. Shasta snowstorm of 1959 greatly benefitted from the products in the reanalysis dataset. Although the resolution of the dataset was coarse $\left(2.5^{\circ}\right.$ latitude $\times$ $2.5^{\circ}$ longitude), the evolution of wind and moisture patterns over the wide extent of the Pacific Ocean, and indeed over the northern hemisphere, could be sufficiently ascertained for synoptic-scale and subsynoptic analyses. And through this evolution the breakdown of the blocking pattern over the eastern and northern Pacific Ocean and the subsequent establishment of the northern and southern branches of the jet stream that phased over northern California could be followed. This phasing was an essential component of the dynamical processes that gave rise to the snowstorm. Yet, could the magnitude of this snowfall in this storm be captured by these large-scale features? The answer is probably not. That is, the important details associated with the mesoscale processes in response to jet stream imbalance-the dynamically induced large-magnitude vertical motions in combination with orographic lift — are truncated by employing the large grid distances in the available analyses. Resolution of these features would require the use of a modern-day high-resolution numerical model such as the Weather Research and Forecasting (WRF) model. Additionally, not only the model, but the data that are employed to initialize the model, must be representative of the small-scale structures present in the fields a day or two before onset of the event.

In spite of these shortfalls of the coarse-resolution analysis, this post-mortem large-scale analysis of Mt. Shasta snowstorm gives critically important information about atmospheric signatures that portend an extreme event. These signatures became apparent over the entire Pacific Ocean several weeks before the event. These conditions are not likely to guarantee an extreme event. But it is likely that these conditions are necessary (i.e., if the extreme event occurs, then some semblance of these signatures would be present). There needs to be abundant moisture and deep convection that transport water vapor to high tropospheric levels, and the strong current in the southern branch of the jet must transport this vapor to the West Coast where it must be linked or phased with the northern branch of the cold polar stream with its imbalance about the jet streak. It is likely that the jet spans the entire Pacific Ocean basin and that the moisture plume reflects that long structure. There is a 
very strong meridional variation of temperature supporting the jet with Arctic air to the north and tropical air to the south. The length of the coherent, unbroken jet streak is one of the most important signals of the impending event. Additionally, RW breaking often occurs as the exit region of the jet streak interacts with the downstream ridge over the eastern Pacific. Now we have the ingredients for mesoscale transverse circulations about the jet with large-magnitude lift and copious production of snow over the mountains. These identified ingredients are important signals for operational forecasters in order to identify the potential for extreme snowfall events having these synoptic and mesoscale patterns.

Refinement of this study will be possible in our age of technologically advanced instrumentationespecially those products derived from remote observations on weather satellites. In particular, the routinely available cloud-tracked winds at low, mid, and high levels of the troposphere give evidence of the large-scale circulation structures. Further, the infrared radiances atop deep cumulus give some idea of the depth of these clouds that supply vapor to the upper levels of the troposphere. Additionally, the simulations with state-of-the-art dynamical models like WRF are likely to be faithful to some of the mesoscale features that lead to the extreme snowfall. Indeed, we look forward to refinement of our research results that can hopefully increase our knowledge of these extreme snowstorms.

Acknowledgements. The authors thank (1) the residents of Mount Shasta City who participated in the survey, thus providing historical accounts of this snowstorm, and (2) Dennis Freeman, the director of the Mt. Shasta Collection at College of the Siskiyous. Additional thanks are given to Chris Haynes, from Humboldt State University, for sparking the interest and motivation for this particular research.

\section{REFERENCES}

Abatzoglou, J. T., and G. Magnusdottir, 2006: Planetary wave breaking and nonlinear reflection: Seasonal cycle and interannual variability. J. Climate, 19, 6139-6152.

Asbell, F., 1959a: Heavy storm closes Everitt Road Friday. Mount Shasta Herald, 19 February, 1st ed., C1.

1959b: Mt. Shasta ski bowl summary. Mount Shasta Herald, 12 February, 1st ed., C1.

, 1960: 1959 weather highlights for the Mount Shasta area. Mount Shasta Herald, 14 January, 10th ed., C1.
Bjerknes, J., 1951: Extratropical cyclones. Compendium of Meteorology. T. F. Malone, Ed., Amer. Meteor. Soc., 577-598.

Bosart, L. F., and G. M. Lackmann, 1995: Postlandfall tropical cyclone reintensification in a weakly baroclinic environment: A case study of Hurricane David (September 1979). Mon. Wea. Rev., 123, 3268-3291.

Browning, K. A., 1986: Conceptual models of precipitation systems. Wea. Forecasting, 1, 23-41.

Businger, S. and R. J. Reed, 1989: Cyclogenesis in cold air masses. Wea. Forecasting, 4, 133-156.

Changnon, S. A., 2006: Problems with heavy snow data at first-order stations in the United States. J. Atmos. Oceanic Technol., 23, 1621-1624.

Dettinger, M. D., 2011: Climate change, atmospheric rivers and floods in California-A multimodel analysis of storm frequency and magnitude changes. J. Amer. Water Resour. Assoc., 47, 514-523.

, D. R. Cayan, M. K. Meyer, and A. E. Jeton, 2004: Simulated hydrologic responses to climate variations and change in the Merced, Carson, and American river basins, Sierra Nevada, California, 1900-2099. Clim. Change, 62, 283-317.

, and Coauthors, 2012: Design and quantification of an extreme winter storm scenario for emergency preparedness and planning exercises in California. Nat. Hazards, 60, 1085-1111.

DeVoto, B., 1943: The Year in Decision 1846. Little, Brown and Company, $576 \mathrm{pp}$.

Freeman, L., cited 2011: Historical Storms of Mount Shasta. [Available online at www.siskiyous.edu/shasta/env/ storm/.]

Guan, B., N. P. Molotch, D. E. Waliser, E. J. Fetzer, and P. J. Neiman, 2010: Extreme snowfall events linked to atmosphere rivers and surface air temperature via satellite measurements. Geophys. Res. Lett., 37, L20401, doi:10.1029/2010GL044696.

Hamilton, D. W., Y.-L. Lin, R. P. Weglarz, and M. L. Kaplan, 1998: Jetlet formation from diabatic forcing with applications to the 1994 Palm Sunday tornado outbreak. Mon. Wea. Rev., 126, 2061-2089.

Hansen, C., and S. J. Underwood, 2012: Synoptic scale weather patterns and large class V slab avalanches on Mt. Shasta, California. Northwest Sci., 86, 329-341.

Higgins, R. W., A. Leetmaa, and V.E. Kousky, 2002: Relationships between climate variability and winter temperature extremes in the United States. J. Climate, 15, 1555-1572.

Holton, J. R., 1983: The dynamics of large scale atmospheric motions. Rev. Geophys., 21, 1021-1027.

Kalnay, E., and Coauthors, 1996: The NCEP/NCAR 40year reanalysis project. Bull. Amer. Meteor. Soc., 77, 437-471.

Kaplan, M. L., Y.-L. Lin, D. W. Hamilton, and R. A. Rozumalski, 1998: The numerical simulation of an unbalanced jetlet and its role in the Palm Sunday 1994 
tornado outbreak in Alabama and Georgia. Mon. Wea. Rev., 126, 2133-2165.

, C. S. Adaniya, P. J. Marzette, K. C. King, S. J. Underwood and J. M. Lewis, 2009: The role of upstream midtropospheric circulations in the Sierra Nevada enabling leeside (spillover) precipitation. Part II: A secondary atmospheric river accompanying a midlevel jet. J. Hydrometeor., 10, 1327-1354.

Keyser, D., and M. A. Shapiro, 1986: A review of the structure and dynamics of upper-level frontal zones. Mon. Wea. Rev., 114, 452-499.

Krick, I. P., and R. Flemming, 1954: Sun, sea and sky. J. Farm Econ., 37, 173-175.

McIntyre, M. E., and T. N. Palmer, 1983: Breaking planetary waves in the stratosphere. Nature, 305, 593600.

McLaughlin, M., cited 2011: Sierra Nevada Historian, The Sierra Snowfall Record. [Available online at thestormking.com.]

Muir, J., 1877: Snow-storm on Mount Shasta. Harper's New Monthly Magazine, 55, (328), 521-530.

Neiman, P. J., F. M. Ralph, G. A. Wick, Y.-H. Kuo, T.-K. Wee, Z. Ma, G. H. Taylor, and M. D. Dettinger, 2008: Diagnosis of an intense atmospheric river impacting the Pacific Northwest: Storm summary and offshore vertical structure observed with COSMIC satellite retrievals. Mon. Wea. Rev., 136, 4398-4420.

NOAA, cited 2012: National Weather Service Climate Prediction Center. [Available online at www.cpc.ncep.noaa.gov.]

O'Connor, J. F., 1959: The weather and circulation of February 1959. Mon. Wea. Rev., 87, 81-90.

O’Hara, B. F., M. L. Kaplan, and S. J. Underwood, 2009: Synoptic climatological analyses of extreme snowfalls in the Sierra Nevada. Wea. Forecasting, 24, 16101624.

Platzman, G. W., 1968: The Rossby wave. Quart. J. Roy. Meteor. Soc., 94, 225-248.

Ralph, F. M., P. J. Neiman, and G. A. Wick, 2004: Satellite and CALJET aircraft observations of atmospheric rivers over the eastern North Pacific Ocean during the winter of 1997/98. Mon. Wea. Rev., 132, 1721-1745.

Rivière, G., and I. Orlanski, 2007: Characteristics of the Atlantic storm-track eddy activity and its relation with the North Atlantic Oscillation. J. Atmos. Sci. 64, 241266.

Rossby, C.-G., and Coauthors, 1939: Relation between variations in the intensity of the zonal circulation of the atmosphere and the displacements of the semipermanent centers of action. J. Mar. Res. 2, 38-55.

StatSoft, cited 2010: StatSoft Electronic Statistics Textbook. Tulsa, OK. [Available online at www.statsoft.com/ textbook.]

Strong, C., and G. Magnusdottir, 2008: Tropospheric Rossby wave breaking and the NAO/NAM. J. Atmos. Sci., 65, 2861-2876.

Southern, M., 1932: The hard winter of 1889-1890. Searchlight Newspaper. 1st ed., C1.

Uccellini, L. W., R. A. Petersen, P. J. Kocin, K. F. Brill, and J. J. Tuccillo, 1987: Synergistic interactions between an upper-level jet streak and diabatic processes that influence the development of a low-level jet and a secondary coastal cyclone. Mon. Wea. Rev., 115, 22272261.

Underwood, S. J., M. L. Kaplan, and King, K. C., 2009: The role of upstream midtropospheric circulations in the Sierra Nevada enabling leeside (spillover) precipitation. Part I: A synoptic-scale analysis of spillover precipitation and flooding in a leeside basin. $J$. Hydrometeor., 10, 1309-1326.

WRCC, cited 2011. Western Region Climate Center. [Available online at www.wrcc.dri.edu.]

Weaver, R. L., 1962: Meteorology of hydrologically critical storms in California. Hydrometeorological Report No. 37, U.S. Department of Commerce, 207 pp.

Zhu, Y., and R. E. Newell, 1998: A proposed algorithm for moisture fluxes from atmospheric rivers. Mon. Wea. Rev., 126, 725-735. 